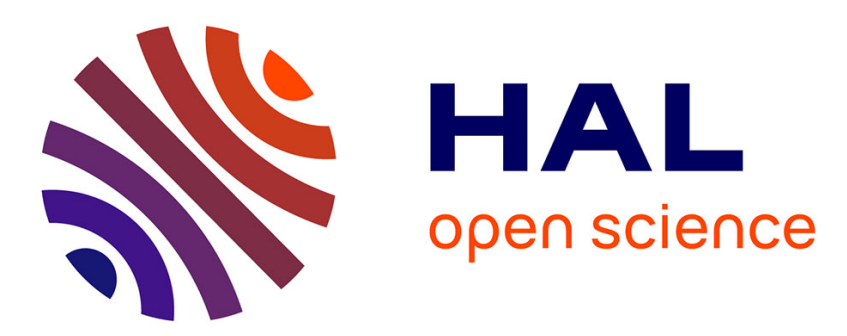

\title{
Reduction of NO emissions from a VOC recuperative incinerator by dilution of the fuel supply
}

\author{
Sylvain Salvador, Yilmaz Kara, Jean-Michel Commandre
}

\section{To cite this version:}

Sylvain Salvador, Yilmaz Kara, Jean-Michel Commandre. Reduction of NO emissions from a VOC recuperative incinerator by dilution of the fuel supply. Applied Thermal Engineering, 2004, $24\left(\mathrm{n}^{\circ} 2-3\right)$, p.245-254. 10.1016/j.applthermaleng.2003.08.007 . hal-01845407

\section{HAL Id: hal-01845407 https://hal.science/hal-01845407}

Submitted on 6 Nov 2018

HAL is a multi-disciplinary open access archive for the deposit and dissemination of scientific research documents, whether they are published or not. The documents may come from teaching and research institutions in France or abroad, or from public or private research centers.
L'archive ouverte pluridisciplinaire HAL, est destinée au dépôt et à la diffusion de documents scientifiques de niveau recherche, publiés ou non, émanant des établissements d'enseignement et de recherche français ou étrangers, des laboratoires publics ou privés. 


\title{
Reduction of NO emissions from a VOC recuperative incinerator by dilution of the fuel supply
}

\author{
S. Salvador *, Y. Kara, J.-M. Commandré \\ Ecole des Mines d'Albi-Carmaux, Laboratoire de Gee'nie de Procee'dee's des Solides Divisee's, UMR \\ CNRS 2392, Campus Jarlard, route de Teillet, 81013 Albi CT cedex 09, France
}

\begin{abstract}
This work demonstrates the possibility of reducing NO emissions from an "in vein" gas burner using a simple and easy to operate technique: the addition of air or of an inert gas to the burner fuel gas feed. A reduction by $30 \%$ can be obtained with air; more than $60 \%$ of NO can be avoided using an inert gas. Several interpretations are proposed to explain the observed reductions in NO emissions. By running the burner at a high load and using the technique of fuel gas dilution, both $\mathrm{CO}$ and $\mathrm{NO}$ emissions can be efficiently lowered.
\end{abstract}

Keywords: NO reduction; Gas burner; Fuel dilution; CO emissions; VOC recuperative incinerator

\section{Introduction}

Recuperative incineration is a process largely used today for the destruction of volatile organic compounds (VOC) present in air streams, prior to their release to the atmosphere [1,2]. The process consists of increasing the temperature of the flow to circa $750{ }^{\circ} \mathrm{C}$ and maintaining this temperature for typically $0.5-1 \mathrm{~s}$, to enable the full oxidation of VOCs into $\mathrm{CO}_{2}$ and $\mathrm{H}_{2} \mathrm{O}$ [3]. This temperature increase is achieved partly by heat recovery from the flue gas, to reach a temperature of about $350{ }^{\circ} \mathrm{C}$. The energy to reach $750{ }^{\circ} \mathrm{C}$ is supplied partly by the combustion of VOC compounds, but this must be supplemented by the combustion of natural gas (NG) in practical applications. For this purpose, an in-stream gas burner is installed inside the incinerator upstream of the incineration chamber, where gases will remain for $0.5-1 \mathrm{~s}$. The temperature homogenisation

\footnotetext{
${ }^{*}$ Corresponding author. Tel.: +33-5-63-49-31-27; fax: +33-5-63-49-32-43.

E-mail address: salvador@enstimac.fr (S. Salvador).
} 


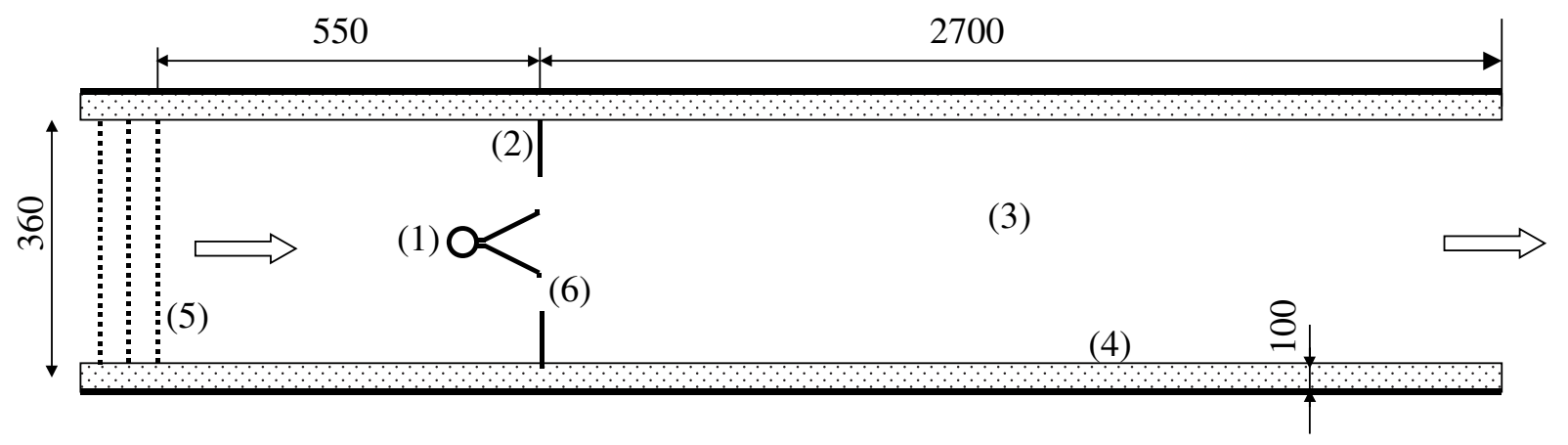

Fig. 1. General assembly of a VOC recuperative incinerator. (1) Burner; (2) diaphragms; (3) combustion chamber; (4) thermal insulation; (5) flow straightener; (6) air veins.

in a cross-section of the combustion chamber is enhanced by the addition of two diaphragms placed above and below the burner wings. These diaphragms generate two large eddies downstream the burner, which mix the hot gases from the burner with the preheated air flow that crosses the air veins [4]. The general assembly of a recuperative incinerator is depicted in Fig. 1.

This process has the advantage that it can treat large air fluxes in a small volume, and above all that it can accept large fluctuations in the VOC concentration: it is able to accept a range of 2-20 $\mathrm{g} \mathrm{m}^{-3}$ at STP [5]. Other features of this reactor, where no catalyst and no porous medium for heat recovery is used, are long life and a very low maintenance cost.

The main performance criterion of such a reactor is the NG consumption to reach the desired VOC destruction efficiency; this target can vary between $95 \%$ and $99.999 \%$, depending on the VOC nature and toxicity [3,5]. Nevertheless, the process is also responsible for the emission of $\mathrm{CO}$ and NO species; the concentrations of these two "secondary pollutants" in the flue gas are performance criteria that must be taken into account [4].

Carbon monoxide is an intermediate specie produced during the thermal degradation of VOCs, and then oxidised in the combustion chamber. It is typically maintained below 80 ppmv (or 100 $\mathrm{mg} \mathrm{m}^{-3}$ at STP), but can exceed thousands of $\mathrm{ppm}$ if the incinerator temperature is decreased by several tens of degrees only [4].

The formation of NO in high temperature flames has been extensively studied in the past. One can refer to classical references in the domain [6-8]. However, few studies were devoted to the examination of NO formation by burners of this type [4,9]. NO species can be produced only by the thermal or prompt NO mechanisms, since neither the NG nor the VOCs contain nitrogen. The wings of these burners classically consist of flat "plates" perforated with several mm diameter holes, through which part of the air flow is directed towards the flame zone of the burner. This air mixes with the NG that is injected upstream on the burner axis. It can be easily observed that small flames are formed, attached to each perforation of the wings. Stansel [9] has shown that NO is formed by those flames that are close to the NG injection. Downstream of the burner wings, a large turbulent flame can be observed, that occupies a volume as high as the burner's wings aperture, and 3-4 time as long as this aperture.

The design of the burners e.g. the angle between the wings, and the number, diameter and position of the perforations is the result of numerous comparative tests that were carried on with the objective to minimise NO emissions while maintaining a stable flame. 
On the basis of this, and with the aim to reduce NO emissions further, it was postulated that one simple way could be to dilute the NG by addition of a non-reactive gas before it is fed to the burner. It can a priori be expected that the decrease in LHV of the fuel should lead to less intense combustion and to less hot local high temperature zones.

In this work, the emissions of NO from a VOC incinerator have been quantified while increasing quantities of dilution gas were added to the NG feed. The dilution gas was alternatively air or nitrogen. Very significant decrease of NO emissions were observed.

Additional tests were carried on with the burner as the only source of energy, e.g. without VOC in the air flow. The NO emissions are again largely decreased. These tests demonstrate that the principle of dilution of a NG fuel supply by addition of a non-fuel gas can be applied to processes other than recuperative incineration.

\section{Experimental section}

The tests were carried on in a pilot scale VOC incinerator fitted with a $320.360 \mathrm{~mm}^{2}$ crosssection, $3 \mathrm{~m}$ long combustion chamber. The burner has a $80 \mathrm{~mm}$ large $300 \mathrm{~mm}$ long aperture, and can generate 75 thermal $\mathrm{kW}$ at full load.

Air preheating is initiated using a flue gas/air heat exchanger, and completed with a $25 \mathrm{~kW}$ electrical heater, to ensure a stable and controlled preheating temperature.

Liquid VOCs were atomised into the air flow downstream of the electrical preheater to reliably achieve a constant concentration.

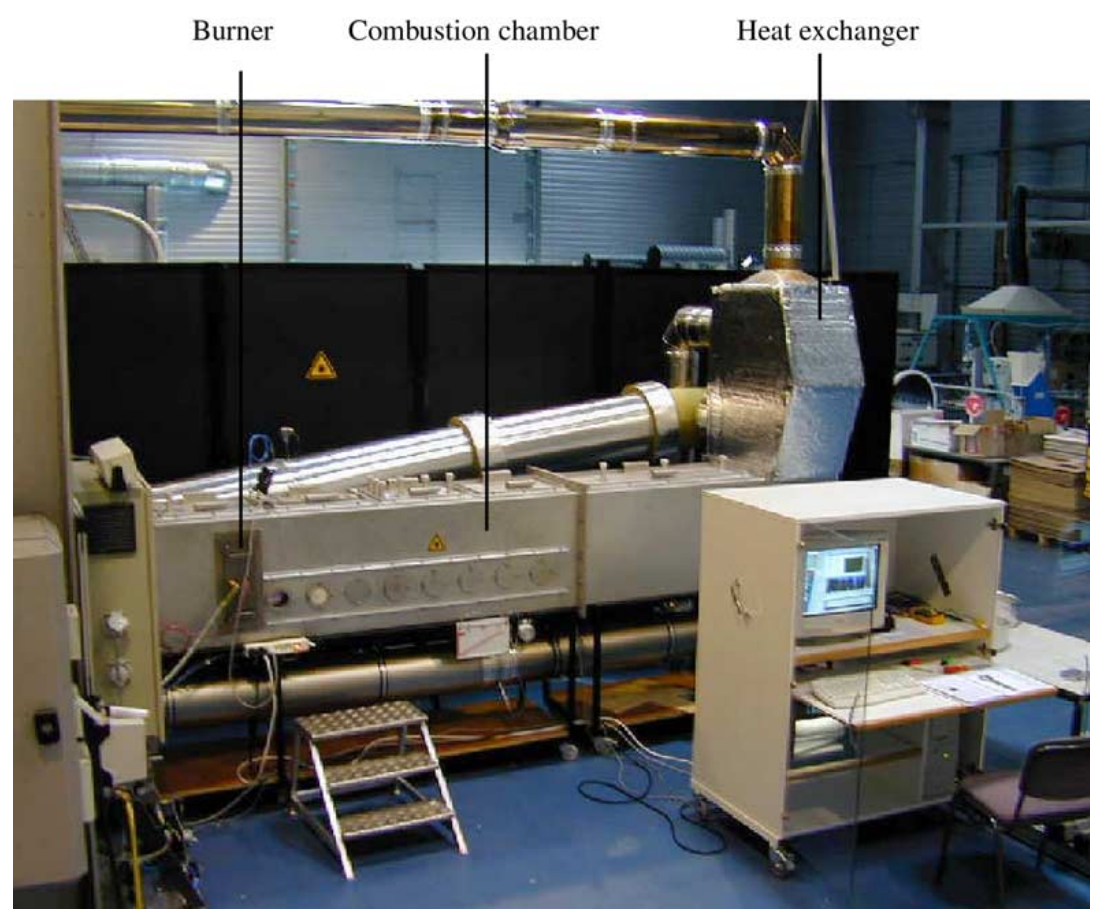

Fig. 2. General view of the VOC incinerator. 
The NG flow rate and the dilution gas flow rate were measured and controlled by mass flow meters/controllers. The air flow rate was measured by a diaphragm and controlled by adjusting the fan rotation speed. Fig. 2 gives a general view of the installation. The flue gas was sampled at the exit of the combustion chamber by a water-cooled sampling probe. The concentrations in $\mathrm{O}_{2}$, $\mathrm{CO}_{2}, \mathrm{CO}$ and $\mathrm{NO}$ were quantified continuously.

As a result of the careful instrumentation of the incinerator, good repeatability in the experiments was possible. The concentration of species in the flue gas did not deviate by more than $5 \%$ when a test was repeated several times.

\section{Results}

\subsection{Case of the incineration of $V O C$}

A first serial of tests was realised with a constant air flow of $468 \mathrm{~m}^{3} \mathrm{~h}^{-1}$ at STP containing 9.1 $\mathrm{g} \mathrm{m}^{-3}$ (at STP) of ethylene acetate, one of the most common VOCs in industrial applications. This flow was preheated to $376^{\circ} \mathrm{C}$ before entering the combustion chamber. The burner was fed with $5.82 \mathrm{~m}^{3} \mathrm{~h}^{-1}$ (at STP) of NG in all tests; this results in a $762{ }^{\circ} \mathrm{C}$ temperature of the flue gas. At these reference conditions, the NO concentration in the flue gas was 21.9 ppmv.

The NG was then diluted by addition of increasing quantities of air, without changing the NG flow rate. We have plotted in Fig. 3 the NO concentration in the flue gas as a function of the flow rate of dilution gas, expressed in non-dimensional form by dividing it by the volumetric NG flow rate. The plot indicates a monotonic reduction in $\mathrm{NO}$ emissions as the dilution ratio is increased. The NO emissions are reduced by approximately one third for the highest dilution ratio. We suspect at this stage that the decrease in NO concentration is not simply due to the dilution of the

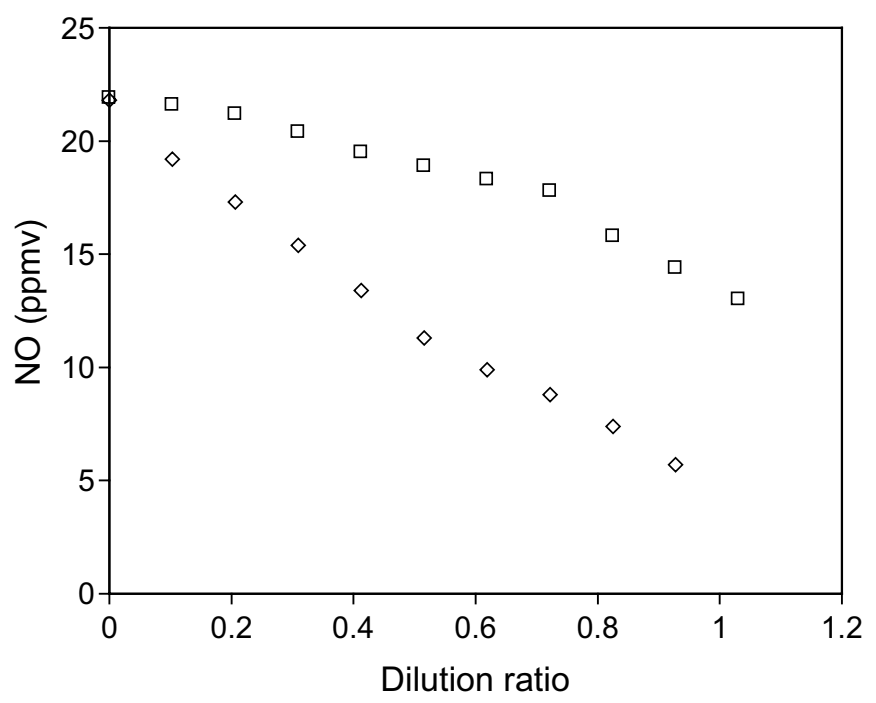

Fig. 3. NO fraction at the exit of the combustion chamber for increasing dilution ratio, using ( $\square)$ air and $(\diamond) N_{2}$ for the case of VOC incineration. 
flue gas by the dilution air which comprises as a maximum $1.2 \%$ of the main air flow, and the flue gas temperature decrease is not measurable.

The combustion chamber was fitted with two "double glazing" quartz windows placed on the top and on one of the lateral faces, so that the flame could be observed. When the NG is not diluted, a blue flame can be observed downstream the burner wings; its height is that of the wings at the beginning, and decreases down to zero at a distance of 3-4 burner apertures. As the dilution ratio is increased, the flame shape is not affected drastically, but the flames tends to shorten down to 2 or 3 burner apertures, and to intensify inside the volume defined by the burner wings.

We have then characterised the effect of $\mathrm{NG}$ dilution by an inert gas $\mathrm{N}_{2}$, instead of air. The results are also plotted in Fig. 3. A decrease in NO concentration is again observed, to a greater extent than in the case of dilution by air: up to $2 / 3$ of the NO can be suppressed. The observation of the flame gave the same trends as in the case of dilution by air.

\subsection{Case of the combustion of $N G$ only}

A second set of experiments was then carried out in order to characterise the NO emissions from the burner itself. The main air flow rate was $500 \mathrm{~m}^{3} \mathrm{~h}^{-1}$ (at STP), and the preheating temperature was maintained at $400{ }^{\circ} \mathrm{C}$; these conditions are very similar to that of the first test series. The NG flow rate had to be increased to $8.52 \mathrm{~m}^{3} \mathrm{~h}^{-1}$ (at STP) to compensate for the absence of VOC, so that the flue gas temperature reached $725^{\circ} \mathrm{C}$.

At these reference conditions for the case of $\mathrm{NG}$ combustion only, the concentration of $\mathrm{NO}$ in the flue gas was 44.1 ppmv.

The NG was then diluted with an increasing quantity of air until extinction of the flame occured. The impact on NO emissions can be assessed from Fig. 4, where a decrease in NO emissions is again observed. Extinction occurs at a dilution ratio of 1.34.

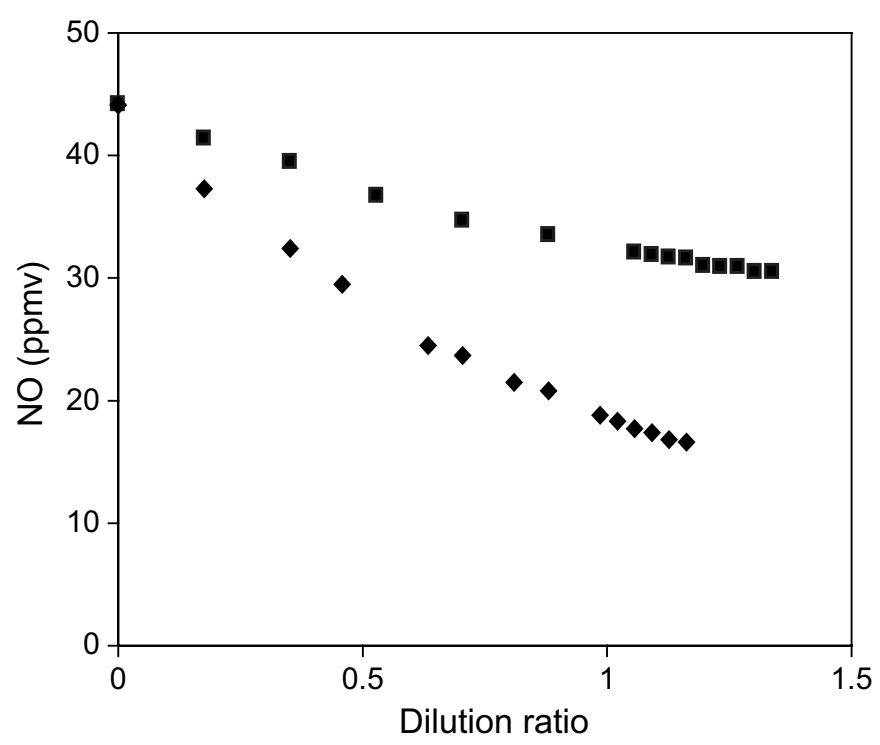

Fig. 4. NO fraction at the exit of the combustion chamber for increasing dilution ratio, using ( $\mathbf{\square})$ air and $(\bullet) \mathrm{N}_{2}$ for the case of the burner alone. 
When $\mathrm{N}_{2}$ is used as the dilution gas, $\mathrm{NO}$ emissions are again decreased, more efficiently than when air is used. The extinction of the flame occurs suddenly for a dilution ratio of 1.16. As far as the flame aspect is concerned, the same behaviour is observed as in the first series of tests; no particular effect on the flame can be observed before it is blown away.

\section{Discussion}

A number of interpretations are proposed below to explain the reduction in NO observed when $\mathrm{NG}$ is diluted with air or $\mathrm{N}_{2}$. The discussion is based upon the comparison between the situations of no dilution, and addition of $\mathrm{N}_{2}$ or air, with a dilution ratio of 1 .

The addition of a dilution gas to the NG feed impacts on a number of phenomena. The direct consequence is that the velocity of the jets in the NG burner is increased, being doubled in the case of a dilution ratio of 1 . The mixing of the fuel gas with air coming through the burner's wings is probably enhanced. In general, intensifying the mixing efficiency tends to increase the flame temperature, and consequently the burner NO emissions.

The burner is fed with three different flows: the NG flow (fuel) which is constant, the air flow coming through the burner wings, which is also constant, and the additional dilution flow. The air flow rate through the wings can be estimated. As a first approach, we can assume that the main air flow is distributed between the burner wings and the veins in proportion to the surfaces offered by the perforation of the wings and the veins surface respectively. Under this assumption, the air flow crossing the wings represents $18 \%$ of the main air flow rate. This percentage has been confirmed by a full hydrodynamic simulation of the incinerator that indicated a value of $15 \%$. The bulk equivalence ratio $(\Phi)$, which is defined below, is 0.907 . The combustion is globally fuel poor, but close to stoichiometric.

$$
\Phi=\frac{\frac{m_{\text {fuel }}}{m_{\text {air }}} \text { actual }}{\frac{m_{\text {fuel }}}{m_{\text {air }}} \text { stoichiometric }}
$$

When a dilution gas is added (dilution ratio $=1$ ), $\Phi$ is decreased to 0.83 . The theoretical adiabatic flame temperature is directly linked to $\Phi$; the injection of air or $\mathrm{N}_{2}$, already present in excess, will decrease its value from 2261 to $2129^{\circ} \mathrm{C}$. It is known that due to the thermal exchanges between the flame and its environment, the actual flame temperature is much lower than this, and is closer to $1500{ }^{\circ} \mathrm{C}$, a temperature that can be considered as a temperature threshold for NO formation [3,10]. This decrease in the flame temperature of approximately $130{ }^{\circ} \mathrm{C}$ can therefore explain the observed reduction in $\mathrm{NO}$ emissions in both cases of dilution by $\mathrm{N}_{2}$ and of dilution by air.

One can also consider the evolution with time of the local values of the equivalence ratio, starting from the NG injection point. In the case of no dilution, the local richness is infinity at the injection point, and decreases to a value of 0.907 that would be reached if all the gases fed to the burner mixed without combustion. When the $\mathrm{NG}$ is diluted with air or $\mathrm{N}_{2}, \Phi$ is only 9.9 at the injection point, and subsequently decreases to 0.83 . These two evolutions have been represented in Fig. 5. 


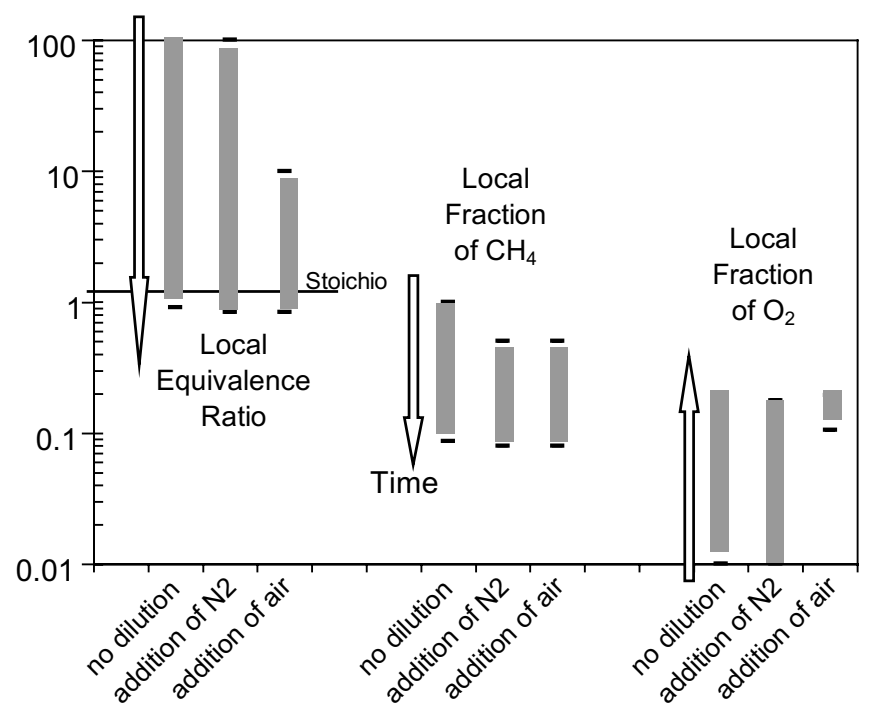

Fig. 5. Evolution with time of the local equivalence ratio, of the local fraction of $\mathrm{CH}_{4}$ and of the local fraction of $\mathrm{O}_{2}$, starting from the fuel gas injection point.

The above consideration would imply that the situations of adding air or $\mathrm{N}_{2}$ were equivalent. Nevertheless, if one considers the rates of the combustion reaction of $\mathrm{NG}$ and of the formation $\mathrm{NO}$, the relevant quantities to be considered are the concentrations of the species. We will express them below as molar fractions $\mathrm{X}$. When no dilution is operated, $\mathrm{X}_{\mathrm{CH}_{4}}$ decreases from 1 at the injection point down to a final value of 0.086 that would result from the mixing of all the gases fed to the burner. When a dilution ratio of 1 is used, the initial $\mathrm{X}_{\mathrm{CH}_{4}}$ is only 0.5 , and would decrease to 0.0796. This evolution is also represented in Fig. 5. The dilution, by lowering $\mathrm{X}_{\mathrm{CH}_{4}}$ at any location, probably leads to a decrease in the local combustion rates, and consequently to a decrease in the local flame intensities and temperatures.

Oxygen will act both on the kinetics of $\mathrm{CH}_{4}$ oxidation and on $\mathrm{NO}$ formation. In the case of pure $\mathrm{CH}_{4}$ feed, $\mathrm{X}_{\mathrm{O}_{2}}$ increases from 0 at the injection to 0.192 (if no combustion occurred). With $\mathrm{N}_{2}$ as diluent, $\mathrm{X}_{\mathrm{O}_{2}}$ increases from 0 to 0.177 . In the case of dilution with air, oxygen is present from the initial time with $\mathrm{X}_{\mathrm{O}_{2}}=0.105$, and would increase up to 0.193 if no combustion occurred. These evolutions have been represented in Fig. 5. It is clear that when air is used as the dilution gas, $\mathrm{X}_{\mathrm{O}_{2}}$ is higher at the beginning of the combustion. This enhances more rapid oxidation of the $\mathrm{NG}$, and consequently higher local temperatures, which will enhance NO formation. In this case, the formation of $\mathrm{NO}$ is additionally enhanced by a more rapid reaction rates resulting from higher $\mathrm{X}_{\mathrm{O}_{2}}$.

The results, grouped together in Fig. 5, indicate that none of the three situations - no dilution, addition of $\mathrm{N}_{2}$ and addition of air-are similar. It is not possible here to distinguish the contribution of the different factors affected by the dilution to increase or decrease NO emissions. The dilution of the flame zone with the air or nitrogen decreases the adiabatic flame temperature, so that less NO is formed in both cases. In the case of dilution with air, the presence of oxygen at the very beginning of the combustion is likely to enhance thermal NO formation through two mechanisms: the increase in the combustion kinetics and the increase in NO formation reaction 
rate. This is probably the reason why less $\mathrm{NO}$ is observed when $\mathrm{N}_{2}$ is used as the dilution gas than when air is used.

The emissions in NO can also be expressed as an NO emission index, NOEI, defined as the mass of $\mathrm{NO}$ produced for one $\mathrm{kg}$ of $\mathrm{NG}$ burned, in $\mathrm{g}_{\mathrm{NO}} \mathrm{kg}_{\mathrm{CH}_{4}}^{-1}[11,12]$. When the burner is fed at $17 \times 10^{-4} \mathrm{~kg} \mathrm{~s}^{-1}$ of NG (burner alone), the NOEI is 4.86 . These values can be compared with the results of Stansel [9], conducted on a burner with very similar design. The values they report for NOEI range between 0.5 and $3 \mathrm{~g}_{\mathrm{NO}} \mathrm{kg}_{\mathrm{CH}_{4}}^{-1}$. The high values we obtain are probably a consequence of the high thermal power density in our case, $0.0708 \mathrm{~g}_{\mathrm{NG}} \mathrm{s}^{-1} \mathrm{~m}^{-2}$ as compared with the maximum thermal power density they employed: $0.0314 \mathrm{~g}_{\mathrm{NG}} \mathrm{s}^{-1} \mathrm{~m}^{-2}$. The thermal power density used here is the ratio between the NG flow rate - that determines the thermal power-and the burner aperture area (height $\times$ length). The authors indeed demonstrate that the NOEI increases when the fuel flow rate is increased; for a given burner, increasing the fuel flow rate increases the thermal power density. This result was used here to enable the comparison between burners of different sizes.

Fig. 6 shows that the addition of air in the NG can reduce by 30\% approximately the NOEI. Using $\mathrm{N}_{2}$ can reduce the NOEI to less than 1 in the case of the incineration of VOC, which represents only one third of the nominal emissions.

NOEI decrease to 3.30 when the burner is fed at $11.6 \times 10^{-4} \mathrm{~kg} \mathrm{~s}^{-1}$ of $\mathrm{NG}(\mathrm{COV}+$ burner). This can be explained by the lower power density used.

The emissions of $\mathrm{CO}$ have also to be considered. During the reference test for the burner alone (no VOC), the $\mathrm{CO}$ emission index is $1.1 \mathrm{~g}_{\mathrm{CO}} \mathrm{kg}_{\mathrm{CH}_{4}}^{-1}$. When dilution of the $\mathrm{NG}$ is operated, with air or with $\mathrm{N}_{2}$, the COEI does not exceed $1.3 \mathrm{~g}_{\mathrm{CO}} \mathrm{kg}_{\mathrm{CH}_{4}}^{-1}$. These values are very low as compared with the results from Stansel who registered values ranging between 5 and $50 \mathrm{~g}_{\mathrm{CO}} \mathrm{kg}_{\mathrm{CH}_{4}}^{-1}$. We think that the low values obtained with our burner are due to the high power density used, as mentioned before. This probably results in a higher flame temperature - which generates more NO-but which also oxidizes $\mathrm{CO}$ into $\mathrm{CO}_{2}$ more efficiently.

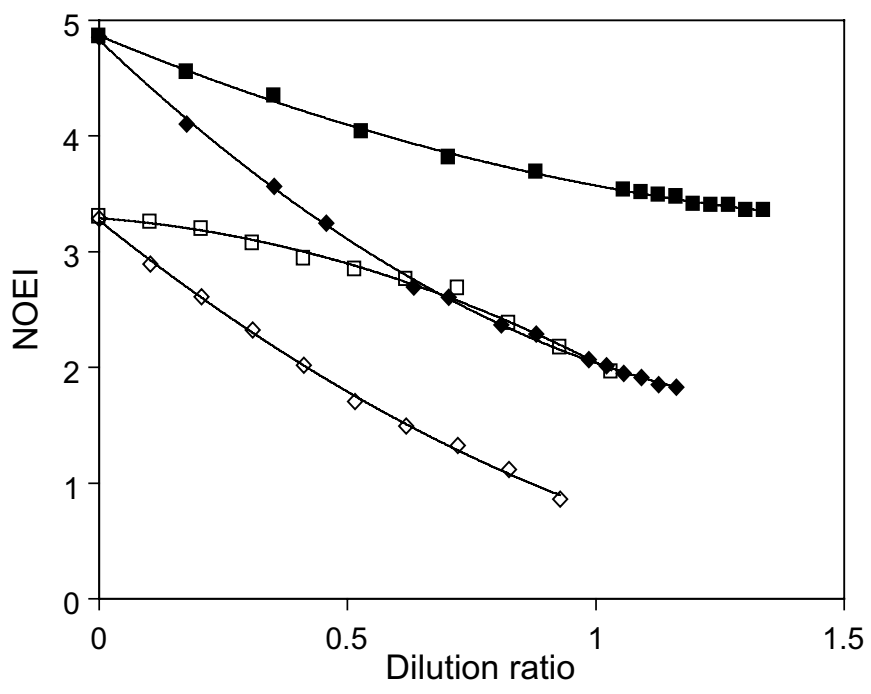

Fig. 6. Evolution of NOEI versus the dilution ratio, using ( $\square)$ air or $(\bullet) \mathrm{N}_{2}$ in the case of the burner alone, and using $(\square)$ air or $(\diamond) \mathrm{N}_{2}$ in the VOC incineration application. 


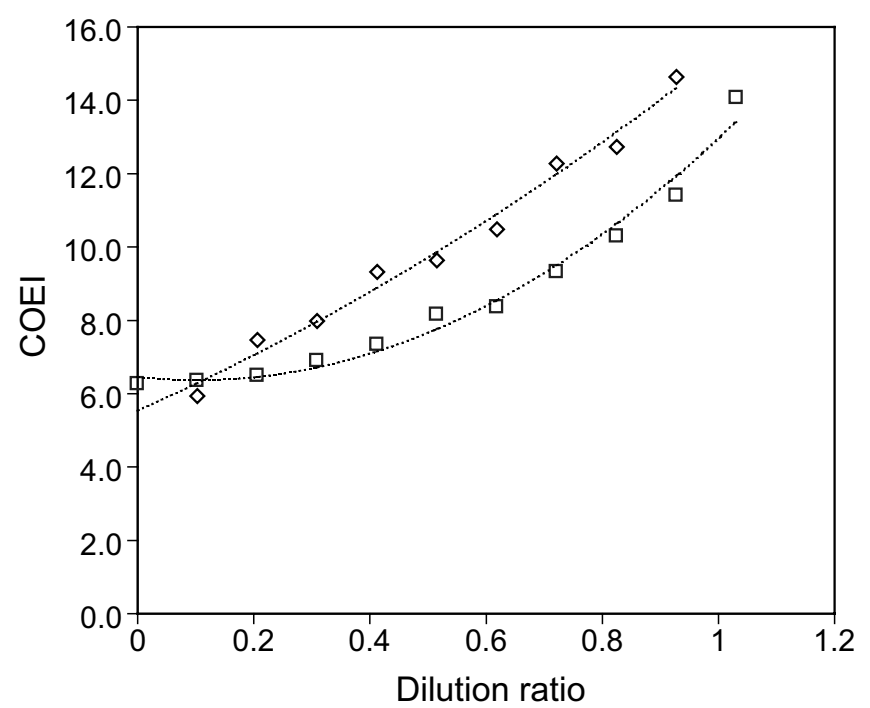

Fig. 7. Evolution of COEI versus the dilution ratio, using $(\square)$ air or $(\diamond)$ nitrogen, in the case of VOC incineration.

During the tests for VOC incineration, the COEI was slightly increased when the dilution ratio was increased. This is illustrated in Fig. 7. The globally higher values are probably due to the lower load for the burner when VOC is incinerated at lower power density in the burner and consequently with less efficient oxidisation of $\mathrm{CO}$. The dilution of the $\mathrm{NG}$, by decreasing the flame temperature, reduces further the oxidisation of $\mathrm{CO}$. The dilution with air increases the $\mathrm{O}_{2}$ content of the flame zone, and helps in the destruction of $\mathrm{CO}$ as compared with the case of dilution by $\mathrm{N}_{2}$.

\section{Conclusion}

We have demonstrated that the addition to the NG feed of the burner of air or of an inert gas, is a very efficient way to reduce NO emissions. This was established both in the case of the burner alone, and in the case of the utilisation of the burner for VOC oxidation purposes. The reduction is circa $30 \%$ for the addition of air, and $60 \%$ approximately for the addition of $\mathrm{N}_{2}$.

In both cases of addition of air or $\mathrm{N}_{2}$, the NO reduction can be explained by a decrease in the adiabatic flame temperature and by the decrease in local mass fraction of $\mathrm{CH}_{4}$ at any location inside the burner, which slows down its oxidation and reduces local temperatures. Air leads to less efficient $\mathrm{NO}$ reductions than $\mathrm{N}_{2}$ probably because its presence at the very beginning of the combustion accelerates the oxidation of $\mathrm{CH}_{4}$ and increases the local combustion temperature. This presence of air in larger quantities also accelerates the rate of the NO formation reaction. It should be noted that the concept of fuel injection recirculation (FIR) is known to be more efficient for $\mathrm{NO}_{x}$ reduction than classical flue gas recirculation (FGR) in some practical applications. This is nevertheless not observed in laboratory scale devices [13]. The authors conclude that the NOEI might be controlled, in practical applications, by mixing effects and not by kinetics.

When the burner was run at a high power density, two consequences were a low COEI and a high NOEI. The dilution technique leads to a very efficient burner, by reducing the NOEI while 
not increasing the COEI. In the VOC incineration application, the COEI is increased from $6 \mathrm{~g}_{\mathrm{CO}} \mathrm{kg}_{\mathrm{CH}_{4}}^{-1}$ to approximately $14 \mathrm{~g}_{\mathrm{CO}} \mathrm{kg}_{\mathrm{CH}_{4}}^{-1}$, which remains a very good performance.

By operating with dilution ratios lower than one, the flame stability is not affected.

This NO reduction principle is similar in some ways to recirculation of flue gases. It can be seen as a reduction of the LHV of the fuel, and can be generalised to any other "vein burner", since the flame stability can be guaranteed. The application of this principle is very easy, since no modification is required to the burner or to the installation using it, with the need only for some external pipe connections. For practical applications, any flue gas containing small quantities of oxygen could be added to the fuel feed, in order to save the cost of an industrial $\mathrm{N}_{2}$ supply.

\section{References}

[1] E.N. Ruddy, L.A. Caroll, Select the best VOC control strategy, Chemical Engineering Progress 89 (7) (1993) $28-35$.

[2] D.R. Van Der Vaart, E.G. Marchand, A. Bagely-Pride, Thermal and catalytic incinerators for the controls of volatile organic compounds, Journal of Air and Waste Management Association 41 (1) (1991) 92-98.

[3] L. Bussac, E. Caverne, Veille technologique sur le traitement des COV, CERUG/GDF 962696, 1996.

[4] Y. Kara, Oxydation thermique des Composés Organiques Volatils en épurateur récupératif-Optimisation des outils de dimensionnement, Thèse de Doctorat (PhD) de l'INP Toulouse, France, 2003.

[5] B. Mortgat, Traitement des COV_Les procédés d'incinération pour anticiper sur le futur bilan solvant, Environnement \& Technique No. 168, 1997, pp. 23-27.

[6] Y.B. Zeldovich, P.Y. Sadovnikov, Oxidation of nitrogen in combustion, Academy Science of USSR, Institute of Chemical Physics, Moscow, Leningrad, 1947.

[7] C.T. Bowman, Control of combustion - generated nitrogen oxide emissions: technology driven by regulation, 24th International Symposium on Combustion, The Combustion Institute, 1992, pp. 859-878.

[8] J. Warnatz, $\mathrm{NO}_{x}$ formation in high temperature processes, Von Karman Institute, Rhode St Genèse, Belgium, 1994.

[9] D.M. Stansel, N.M. Laurendeau, D.W. Senser, $\mathrm{CO}$ and $\mathrm{NO}_{x}$ emissions from controlled-air burner: experimental measurements and exhaust correlations, Combustion Science and Technology 104 (4-6) (1995) 207-234.

[10] S.R. Turns, F.H. Myhr, Oxides of nitrogen emissions from turbulent jet flames: Part I-Flames effects and flame radiation, Combustion and Flame 87 (3-4) (1991) 319-335.

[11] T. Takeno, M. Nishioka, Species conservation and emission indices for flames described by similarity solutions, Combustion and Flame 92 (4) (1993) 465-468.

[12] L.G. Blevins, J.P. Gore, Computed structure of low strain rate partially premixed $\mathrm{CH}_{4} /$ air counterflow flames: implications for NO formation, Combustion and Flame 116 (4) (1999) 546-566.

[13] J.J. Feese, S.R. Turns, Nitric oxide emissions from laminar diffusion flames: effects of air-side versus fuel-side diluent addition, Combustion and Flame 113 (1998) 66-78. 